\title{
The climatic factors affecting dengue fever outbreaks in southern Taiwan: an application of symbolic data analysis
}

\author{
Yi-Horng Lai ${ }^{*}$
}

From International Conference on Biomedical Engineering Innovation (ICBEI) 2016 Taichung, Taiwan. 28 October - 1 November 2016

${ }^{*}$ Correspondence: FL006@mail.oit.edu.tw Department of Health Care Administration, Oriental Institute of Technology, No. 58, Sec. 2, Sichuan Rd., Banqiao Dist., New Taipei City 22061, Taiwan

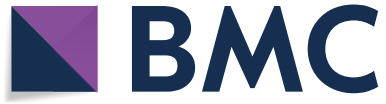

(c) The Author(s) 2018. This article is distributed under the terms of the Creative Commons Attribution 4.0 International License (http://creativecommons.org/licenses/by/4.0/), which permits unrestricted use, distribution, and reproduction in any medium, provided you give appropriate credit to the original author(s) and the source, provide a link to the Creative Commons license, and indicate if changes were made. The Creative Commons Public Domain Dedication waiver (http://creativecommons.org/publicdomain/zero/1.0/) applies to the data made available in this article, unless otherwise stated. 
the most vulnerable area in developing countries. The outbreaks do not only occur in rural areas but also in urban areas.

Taiwan is located in the Pacific Ocean region and is a hotbed of dengue vectors because of its high temperature and humidity [4]. The risk of dengue fever has increased gradually in southern Taiwan and has become a major public health issue that affects the quality of life and the health of Taiwan's residents. During the first half of the twentieth century, there were three dengue fever outbreaks in Taiwan $(1915,1931$, and 1942). After almost 40 years of dormancy, a dengue fever outbreak reoccurred in 2002 in southern Taiwan. The total number of indigenous cases in this outbreak was 5336, including 241 cases of dengue hemorrhagic fever (DHF) that caused 19 deaths. After that, the indigenous dengue cases were less than 400 in 2003-2005. Since 2006, Taiwan has faced dengue fever outbreaks of different scales every year; the cases were concentrated mainly in southern Taiwan, including Kaohsiung City, Tainan City, and Pingtung County. In 2015, Taiwan battled one of the most severe dengue outbreaks in history with over 42,000 dengue cases-22,741 cases in Tainan City, 18,933 cases in Kaohsiung City, and 373 cases in Pingtung City-and 228 deaths found to be associated with dengue infection [5].

Previous studies have been carried out on the correlation between climate factors and dengue fever using a wide spectrum of mathematical and statistical modeling methods [6-10]. Findings from most previous studies in other parts of the world also showed that climatic variables have an effect on dengue fever transmission. Studies in Taiwan [6, 1113], Singapore [14], Vietnam [8, 15], Thailand [7, 16], China [9, 17], Trinidad [18, 19], Malaysia [20], Puerto Rico [21], Cambodia [10], and Saudi Arabia [22] showed a significant correlation between dengue fever incidence and temperatures, precipitation, and sunshine.

As temperature increases, the Aedes aegypti mosquito displays shorter periods of development in all stages of their life cycle, which leads to increased population growth. The mosquito feeding rate also increases; and dengue fever viruses in adult Aedes aegypti mosquitoes require shorter incubation periods to migrate to salivary glands $[6-10,14$, 23]. Specifically, increasing temperatures increases the available habitat for the dengue fever vector, the Aedes aegypti mosquito, while concurrently increasing both the longevity of the virus and the mosquito [14]. Higher temperatures can also shorten the duration of virus replication, and increase mosquito reproduction and contacts with humans [9]. If temperature increases by approximately $3{ }^{\circ} \mathrm{C}$, mean incidence rates during epidemics can double [24]. Warmer temperatures can increase the transmission rates of dengue fever in various ways. It may allow vectors to survive and reach maturity much faster than at lower temperatures [25]. Moreover, it may also reduce the size of mosquito larvae resulting in smaller adults that have high metabolism rates, requiring more frequent blood meal and need to lay eggs more often [25].

Some studies reported that rainfall can lead to increases in dengue fever transmission. They suggested that rainfall creates abundant outdoor breeding sources for Aedes aegypti, and the water storage containers also can serve as breeding habitats. Bhatt, Gething, Brady, Messina, Farlow, Moyes, Drake, Brownstein, Hoen, Sankoh, Myers, George, Jaenisch, Wint, Simmons, Scott, Farrar, and Hay paired the resulting risk map with detailed longitudinal information from dengue fever cohort studies, and they predicted dengue fever to be ubiquitous throughout the tropics, with local spatial variations 
influenced strongly by rainfall [23]. Choi, Tang, McIver, Hashizume, Chan, Abeyasinghe, Iddings, and Huy developed negative binomial models using monthly average maximum, minimum, mean temperatures and monthly cumulative rainfall, and they also claimed that rainfall significantly increased the dengue fever incidence [10]. When more consecutive wet days occurred in a period, dengue fever incidence increased. Rainfall leads to an increase in breeding sites of the mosquito vector, which would contribute to the increase in dengue fever occurrence [21]. On the contrary, however, some other studies showed that heavy rainfall can possibly lower dengue fever transmission by reducing the survival rate of the Aedes aegypti mosquito. Wegbreit analyzed weekly dengue fever morbidity data from the twin-island country of Trinidad and Tobago, and he suggested that there is a slightly negative correlation with the precipitation [26]. Thammapalo, Chongsuwiwatwong, McNeil, and Geater determine the independent effects of rainfall [16] in Thailand, and they also found that increased rainfall is associated with a decreased incidence of dengue fever cases in some provinces. Alshehri [22] aimed to address the effects of heavy rainfall on Aedes aegypti mosquito density in Saudi Arabia, and he argued that dengue fever has negative correlation with rainfall and humidity.

Sunshine is also closely linked to other ecological factors such as temperature and humidity and thereby might affect the dengue fever incidence [15]. Correlation studies carried out on monthly dengue fever cases have found the risk of dengue fever to be inversely associated with duration of sunshine [8]. With the monthly data in Vietnam, Vu, Okumura, Hashizume, Tran, and Yamamoto indicated that there is a significant negative association between dengue fever cases and the hours of sunshine [15]. Wongkoon, Jaroensutasinee, Jaroensutasinee investigated the effect of seasonal variation on the abundance of Aedes aegypti mosquito larvae and explored the impact of weather variability on dengue fever transmission in Thailand, and they concluded that maximum temperature, sunshine and evaporation are negatively correlated with dengue fever incidence [19].

However, while most studies claimed that climate is a determinant of dengue fever, some other studies argued that climate factor has no obvious correlation with this disease. They suggested that temperature [18, 27-29] and rainfall [13, 27-29] did not affect dengue fever incidence. The weekly average maximum temperature, total rainfall and the total number of dengue fever cases from 2005 to 2011 were used as time series data in Goto, Kumarendran, Mettananda, Gunasekara, Fujii, and Kaneko's study [27]. They found that weekly average maximum temperatures and the weekly total rainfall did not significantly affect dengue fever incidence in three geographically different areas of Sri Lanka. Pandey, Nagar, Gupta, Khan, Singh, Mishra, Prakash, Singh, Singh, and Jain reported the annual trend of dengue fever virus infection in north India [28], and they indicated that there is no statistical significant correlation between weather data and increasing dengue fever positive cases. In a populationbased study on the effects of climate and mosquito indices on dengue fever in Trinidad, Chadee, Shivnauth, Rawlins, and Chen declared that no significant correlations are observed between temperature and dengue fever [18]. Chang, Lee, Ko, Tsai, Lin, $\mathrm{Chen}, \mathrm{Lu}$, and Chen pointed out that climatic factors correlated significantly with case numbers of many diseases, such as murine typhus and $Q$ fever, but neither temperature nor rainfall correlated with the case number of dengue fever [13]. According 
to the epidemiological investigation, the incidence of dengue fever had no relationship with temperature, or precipitation, and some studies [29] showed a clear relationship only with the sociological factors.

Most of the climatic data are range-type data. Because of the limitation of traditional statistics (e.g., regression analysis), range-type data is difficult to be analyzed. Most of them are analyzed by minimum value (e.g., minimum temperature), maximum value (e.g., maximum temperature), mean value (e.g., mean temperature, mean rainfall), and cumulative value (e.g., cumulative rainfall, cumulative sunshine). Most studies developed linear regression model [6-10] or negative binomial regression model [10] using monthly average temperatures [14, 17], maximum temperatures [7, 27], minimum temperatures [10], mean rainfall [14, 17], cumulative rainfall [27], and cumulative sunshine $[8,15,19]$ over the period for the relationship between dengue fever incidence and climatic data. However, the major drawback of the traditional statistical methods is that when the correlation between dengue fever and each of the above-mentioned value is not consistent, it will be difficult to draw a conclusion [10, 19]. For example, in Choi, Tang, McIver, Hashizume, Chan, Abeyasinghe, Iddings, and Huy's study [10], mean temperature is significantly associated with dengue fever incidence, but dengue fever incidence did not correlate well with the maximum temperature and minimum temperature. Wongkoon, Jaroensutasinee, Jaroensutasinee's study also had the same problem. They investigated the effect of seasonal variation on the abundance of the Aedes aegypti mosquito larvae and explored the impact of weather variability on dengue fever transmission in Thailand, and they found that mean temperature and minimum temperatures are positively associated with dengue fever incidence, but maximum temperature is negatively correlated with dengue fever incidence [19].

With the advent of information technology, very large datasets have become routine. Traditional statistical methods do not have the power or flexibility to analyze these efficiently and extract the required knowledge. Symbolic data analysis is to summarize a large dataset in such a way that the resulting summary dataset is of a manageable size and yet retains as much of the knowledge in the original dataset as possible [30,31]. One consequence of this is that the data may no longer be formatted as single values, but be represented by lists, intervals, distributions, etc. The summarized data have their own internal structure, which must be taken into account in any analysis.

High peaks for dengue outbreak is reported on summer in Taiwan. This suggests that climatic factors are likely to exert potential impact on dengue fever outbreak in tropical or subtropical regions [32,33]. This study is aimed for investigate the relationship between climatic factors and the outbreaks of dengue fever in southern Taiwan with symbolic data analysis and to compare the differential effects of climatic factors on the incidence of dengue fever in southern Taiwan.

\section{Materials and research method}

Climatic factors, such as temperature, rainfall, and sunshine play an important role in the spread of dengue fever viruses. The dengue fever data and climatic data of Kaohsiung city from January 2005 to March 2014 were analyzed with symbolic data analysis for the interval-valued data in this study. 


\section{Study area}

Kaohsiung City is the largest metropolitan city of southern Taiwan with an estimated population of 2,777,784 in 2016. According to the computerized database from the surveillance system of Taiwan's Center for Disease Control, Kaohsiung City had 5543 confirmed dengue fever cases from January 2005 to March 2014, accounting for most of the total cases in Taiwan. Dengue fever transmission has been active in this area, and the latest large-scale outbreak occurred in the end of 2014.

\section{Data collection}

Since 1988, dengue fever has been announced as a Class III Notified Disease in Taiwan, and the data are collected continuously and systematically by Taiwan's Ministry of Health and Welfare with the Taiwan National Infectious Disease Statistics System [34]. The data collection mechanism has been stable over time, and this routinely-collected data can be used for analyzing factors affecting the occurrence of dengue fever. Because the most recent data is subject to update, this study focuses only on the data from January 2005 to March 2014.

Meteorological data on the monthly maximum temperature, minimum temperature, amount of rainfall, and amount of sunshine were obtained from the Climate Statistics Database provided by Taiwan's Central Weather Bureau [35].

The variables that correlate with dengue fever are then submitted to symbolic linear regression analysis. Symbolic data analysis is employed to explore and identify statistically significant risk indicators [33].

\section{Symbolic data analysis}

Symbolic data analysis is a relatively new field that provides a range of methods for analyzing complex datasets. Traditional statistical methods do not have the power or flexibility to make sense of very large datasets, and symbolic data analysis techniques can be developed in order to extract knowledge from such data. The analysis of symbolic data differs from that of the traditional. Rather than identifying points of interest in the data, symbolic data methods allow the user to build models of the data and make predictions about future events [32].

Dengue fever data of Kaohsiung city from January 2005 to August 2014 were analyzed with symbolic linear regression analysis for interval-valued data with R 3.3.2 (with Package RSDA) with SparkR 2.1 in symbolic data analysis with center-method [36, 37]. The regression model equation plots dengue fever incidence (cases) versus temperature $\left({ }^{\circ} \mathrm{C}\right.$ ), accumulated rainfall ( $\mathrm{mm})$, and accumulated sunshine (hours) is as follows:

$$
\begin{aligned}
\text { Dengue fever incidence }= & \beta_{0}+\beta_{1} \times \text { temperature } \\
& +\beta_{2} \times \text { accumulated rainfall } \\
& +\beta_{3} \times \text { accumulated sunshine }
\end{aligned}
$$

Billard and Diday proposed an approach for a constrained linear regression model on the midpoints and range of the interval values [30]. The prediction of the lower and upper boundaries of the interval value of the dependent variable is accomplished from 
its midpoint and range, which are estimated from the fitted linear regression models applied to the midpoint and range of each interval value of the independent variables.

Based on Billard and Diday's study [30], the estimate of the parameters $\beta$ is based only on the midpoint of the intervals according to the criterion considered. Let $E=\left\{\mathrm{e}_{1}, \ldots, \mathrm{e}_{\mathrm{n}}\right\}$ be a set of examples that are described by $\mathrm{p}+1$ interval-valued variables $\mathrm{y}, \mathrm{x}_{1}, \ldots, \mathrm{x}_{\mathrm{p}}$. Each example is represented as an interval quantitative feature vector $\mathrm{z}_{\mathrm{i}}=\left(\mathrm{x}_{\mathrm{i}}, \mathrm{y}_{\mathrm{i}}\right), \mathrm{xi}=\left(\mathrm{x}_{\mathrm{i} 1}, \ldots, \mathrm{x}_{\mathrm{ip}}\right)$, $x_{i j}=\left[a_{i j}, b_{i j}\right] \in \hat{s}=\{[a]:, a, b \in R, a \leq b\}$ where $(\mathrm{j}=1, \ldots, \mathrm{p})$ and $y_{i}=\left[y_{L i}, y_{L i}\right] \in \hat{s}$ are, respectively, the observed values of $x_{j}$ and $y$.

It can be considered that $\mathrm{X}_{1}, \ldots, \mathrm{X}_{\mathrm{p}}$ related to $\mathrm{Y}$ according to the linear regression relationship:

$$
\begin{aligned}
& y_{L i}=\beta_{0}+\beta_{1} a_{i 1}+\cdots+\beta_{p} a_{i p}+\varepsilon_{L i} \\
& y_{U i}=\beta_{0}+\beta_{1} b_{i 1}+\cdots+\beta_{p} b_{i p}+\varepsilon_{U i}
\end{aligned}
$$

From Eq. (2), the sum of the squares of deviations in this first approach is as follows:

$$
S_{c m}=\sum_{i=1}^{n}\left(\epsilon_{L i}+\epsilon_{U i}\right)^{2}=\sum_{i=1}^{n}\left(y_{L i}-\beta_{0}-\beta_{1} \alpha_{i 1}-\cdots \beta_{p} \alpha_{i p}+y_{U i}-\beta_{0}-\beta_{1} b_{i 1}-\cdots \beta_{p} b_{i p}\right)^{2}
$$

which represents the sum of the square of the sum of the lower and upper boundary errors.

Lima Neto and de Carvalho present the estimates of the vector of parameters $\beta$ in matrix notation for the center method [37], which can be rewritten in the simplest form as

$$
y^{C}=X^{C} \beta+\varepsilon^{C}
$$

where $\left.y^{C}=\left(y_{1}^{C}, \ldots y_{n}^{C}\right)^{T}, X^{C}=\left(x_{1}^{C}\right)^{T}, \ldots\left(x_{n}^{C}\right)^{T}\right)^{T},\left(x_{i}^{C}\right)^{T}=\left(1, x_{i 1}^{C}, \ldots x_{i p}^{C}\right) i=1, \ldots, n$ $\beta=\left(\beta_{0}, \ldots, \beta_{p}\right)^{T}$, and $\varepsilon^{C}=\left(\varepsilon_{1}^{C}, \ldots, \varepsilon_{n}^{C}\right)^{T}$.

If $\mathrm{X}_{\mathrm{c}}$ has full rank $(\mathrm{p}+1) \leqq \mathrm{n}$, the least square estimate of $\beta$ in Eq. (3) is given by

$$
\hat{\beta}=\left(\left(X^{C}\right)^{T} X^{C}\right)^{-1}\left(X^{C}\right)^{T} y^{C}
$$

Given a new example e, described by $z=(x, y)$, where $x=\left(x_{1}, \ldots, x_{p}\right)$ with $x_{j}=\left[a_{i}, b_{j}\right]$ $(\mathrm{j}=1, \ldots, \mathrm{p})$, the value $\mathrm{y}=\left[\mathrm{y}_{\mathrm{L}}, \mathrm{y}_{\mathrm{U}}\right]$ of $\mathrm{Y}$ will be predicted by $\hat{y}=\left[\hat{y}_{L}, \hat{y}_{U}\right]$ as follows:

$$
\hat{y}_{L}=\left(x_{L}\right)^{T} \hat{\beta} \text { and } \hat{y}_{U}=\left(x_{U}\right)^{T} \hat{\beta}
$$

where $\left(x_{L}\right)^{T}=\left(1, a_{1}, \ldots, a_{p}\right)$,

$$
\left(x_{U}\right)^{T}=\left(1, b_{1}, \ldots, b_{p}\right) .
$$

The determination coefficient $\left(\mathrm{R}^{2}\right)$ represents a goodness-of-fit measure commonly used in regression analysis to capture the adjustment quality of a model. The determination coefficient $\left(R^{2}\right)$ for the CM method is easily established as

$$
R_{c m}^{2}=\frac{\sum_{i=1}^{n}\left(\hat{y}_{i}^{C}-\bar{y}^{C}\right)^{2}}{\sum_{i=1}^{n}\left(y_{i}^{C}-\bar{y}^{C}\right)^{2}}
$$

However, note that $y^{C}=\left(y_{L}+y_{U}\right)$. Thus, the Eq. (7) can be replaced by 
Table 1 The characteristics of the research data in dengue fever data

\begin{tabular}{llclc}
\hline & N (months) & Total (years) & Mean (months) & S. E. (months) \\
\hline 2005/Jan.-2005/Dec. & 12 & 144 & 12.00 & 15.82 \\
2006/Jan.-2006/Dec. & 12 & 956 & 79.67 & 100.36 \\
2007/Jan.-2007/Dec. & 12 & 202 & 16.83 & 20.60 \\
2008/Jan.-2008/Dec. & 12 & 443 & 36.92 & 48.67 \\
2009/Jan.-2009/Dec. & 12 & 773 & 64.42 & 102.70 \\
2010/Jan.-2010/Dec. & 12 & 1106 & 92.17 & 122.07 \\
2011/Jan.-2011/Dec. & 12 & 1183 & 98.58 & 143.43 \\
2012/Jan.-2012/Dec. & 12 & 532 & 44.33 & 57.98 \\
2013/Jan.-2013/Dec. & 12 & 102 & 8.50 & 9.74 \\
2014/Jan.-2014/Mar. & 3 & 7 & 2.33 & 3.47 \\
\hline
\end{tabular}

Table 2 The characteristics of the research data in climatic data

\begin{tabular}{lllll}
\hline & $\mathbf{N}$ (months) & $\begin{array}{l}\text { Temperature }\left({ }^{\circ} \mathbf{C}\right) \\
\text { U[lower, upper] }\end{array}$ & $\begin{array}{l}\text { Rainfall (mm) } \\
\text { U[lower, upper] }\end{array}$ & $\begin{array}{l}\text { Sunshine (hours) } \\
\text { U[lower, upper] }\end{array}$ \\
\hline 2005/Jan.-2005/Dec. & 12 & $U[8.7,34.9]$ & $U[0,1030.0]$ & $U[0,259.4]$ \\
2006/Jan.-2006/Dec. & 12 & $U[11.3,35.7]$ & $U[0,901.5]$ & $U[0,224.6]$ \\
2007/Jan.-2007/Dec. & 12 & $U[9.2,35.4]$ & $U[0,1229.3]$ & $U[0,290.6]$ \\
2008/Jan.-2008/Dec. & 12 & $U[10.2,35.0]$ & $U[0,1199.7]$ & $U[0,240.1]$ \\
2009/Jan.-2009/Dec. & 12 & $U[9.3,35.0]$ & $U[0,934.5]$ & $U[0,256.0]$ \\
2010/Jan.-2010/Dec. & 12 & $U[10.9,35.9]$ & $U[0,853.0]$ & $U[0,238.6]$ \\
2011/Jan.-2011/Dec. & 12 & $U[11.3,35.8]$ & $U[0,543.0]$ & $U[0,240.9]$ \\
2012/Jan.-2012/Dec. & 12 & $U[11.0,36.4]$ & $U[0,832.5]$ & $U[0,231.8]$ \\
2013/Jan.-2013/Dec. & 12 & $U[12.0,35.7]$ & $U[0,765.7]$ & $U[0,248.1]$ \\
2014/Jan.-2014/Mar. & 3 & $U[11.1,30.6]$ & $U[0,67.0]$ & $U[0,254.8]$ \\
\hline
\end{tabular}

$$
R_{c m}^{2}=\frac{\sum_{i=1}^{n}\left(\left(\hat{y}_{L i}+\hat{y}_{U i}\right)-\left(\bar{y}_{L i}+\bar{y}_{U i}\right)\right)^{2}}{\sum_{i=1}^{n}\left(\left(y_{L i}+y_{U i}\right)-\left(\bar{y}_{L i}+\bar{y}_{U i}\right)\right)^{2}}
$$

Billard and Diday's method [30] indicate the importance of range-type information in prediction performance as well as the application of inequality constraints to ensure mathematical coherence between the predicted values of the lower and upper boundaries of the interval-value data.

\section{Results}

Using monthly aggregated data, dengue fever data of Kaohsiung city from January 2005 to March 2014 were analyzed with symbolic linear regression analysis for the intervalvalued data in this study. The climatic data in this study includes temperature, rainfall, and sunshine. The type of these data is interval-valued data, and they all can be presented as U[lower, upper], meaning the range of the data is from minimum (lower) to maximum (upper). Details of the dengue fever incidence in Kaohsiung City and the monthly temperature/rainfall/sunshine measurements are presented in Tables 1 and 2 respectively. 


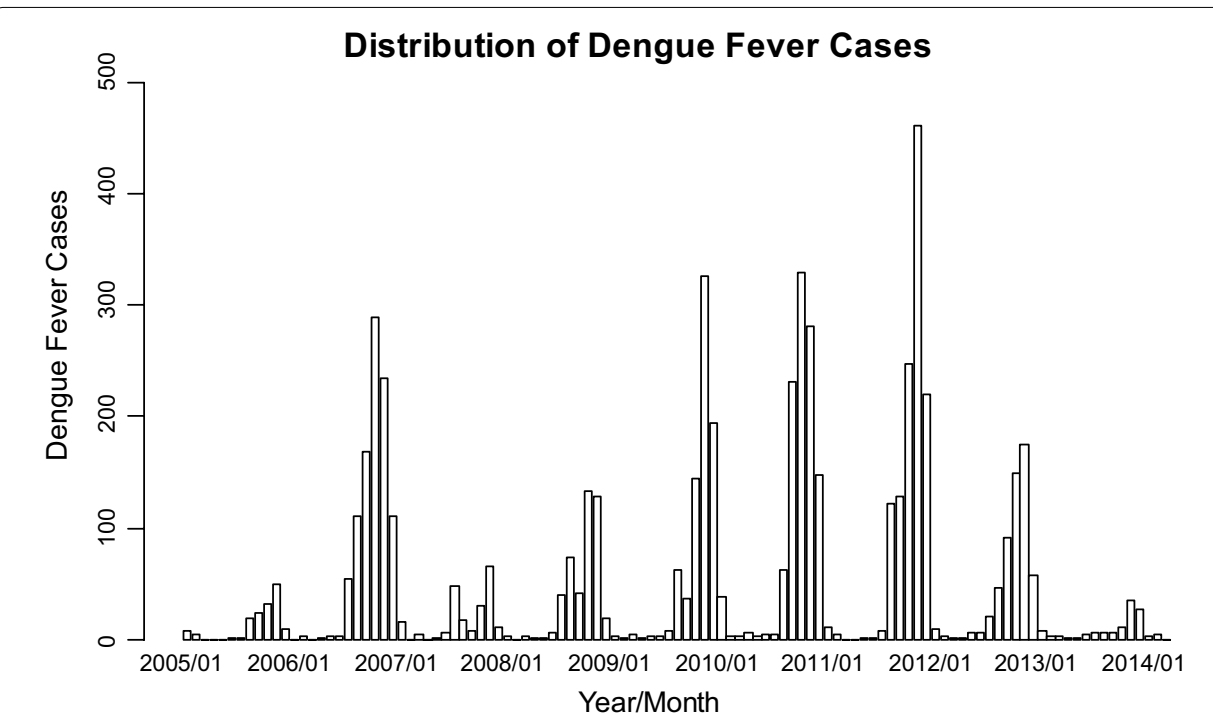

Fig. 1 Distribution of dengue fever cases from January 2005 to March 2014

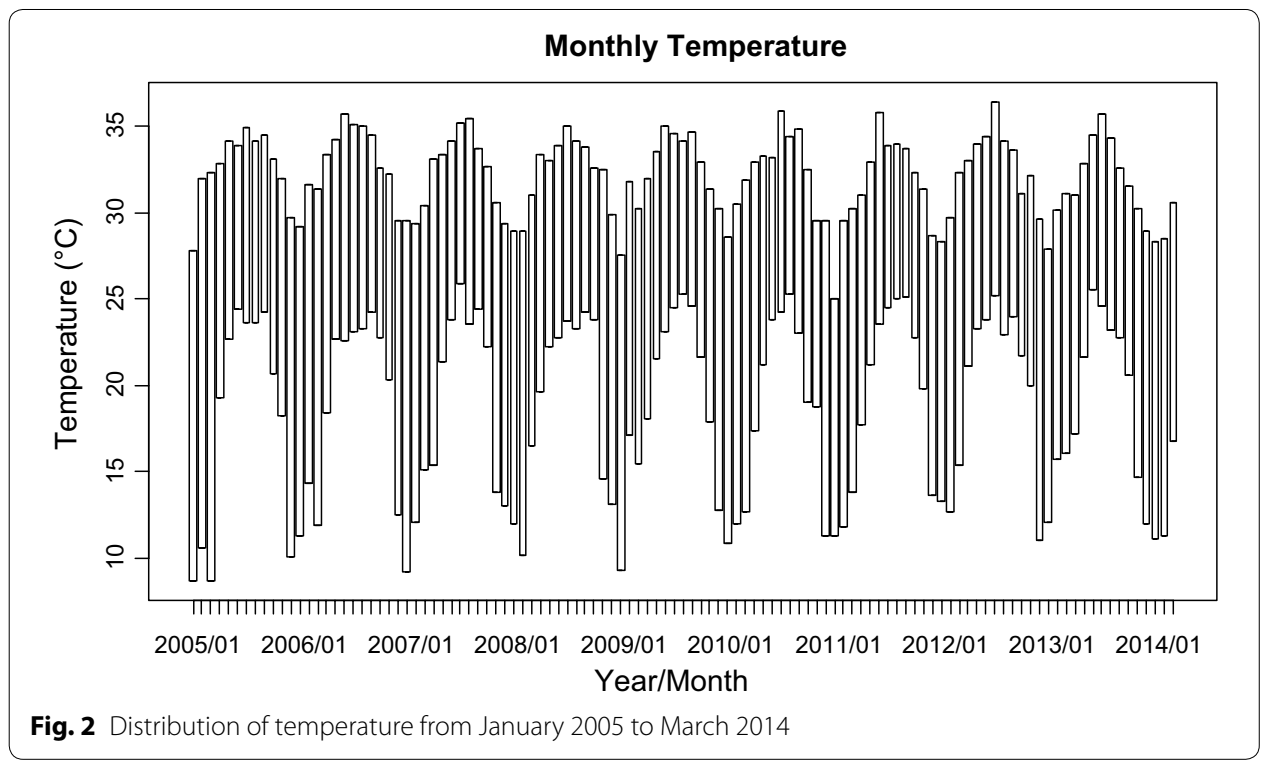

For the 111-month period (January 2005-March 2014), the number of dengue fever cases in Kaohsiung City was from 0 to 462, with the highest one (462 cases) occurred in November 2011 (Fig. 1). The monthly minimum temperature was from $8.7^{\circ} \mathrm{C}$ to $12.0^{\circ} \mathrm{C}$, with the lowest recorded minimum temperature in January 2005 and March 2005. The monthly maximum temperature was from 30.6 to $36.4{ }^{\circ} \mathrm{C}$, with the highest recorded minimum temperature in July 2012 (Fig. 2). The monthly accumulated rainfall measurement was from 0 to $1229.3 \mathrm{~mm}$, with the highest recorded measurement in August 2007 (Fig. 3). The monthly accumulated sunshine measurement was from 0 to $290.6 \mathrm{~h}$, with the highest recorded measurement in July 2007 (Fig. 4). 

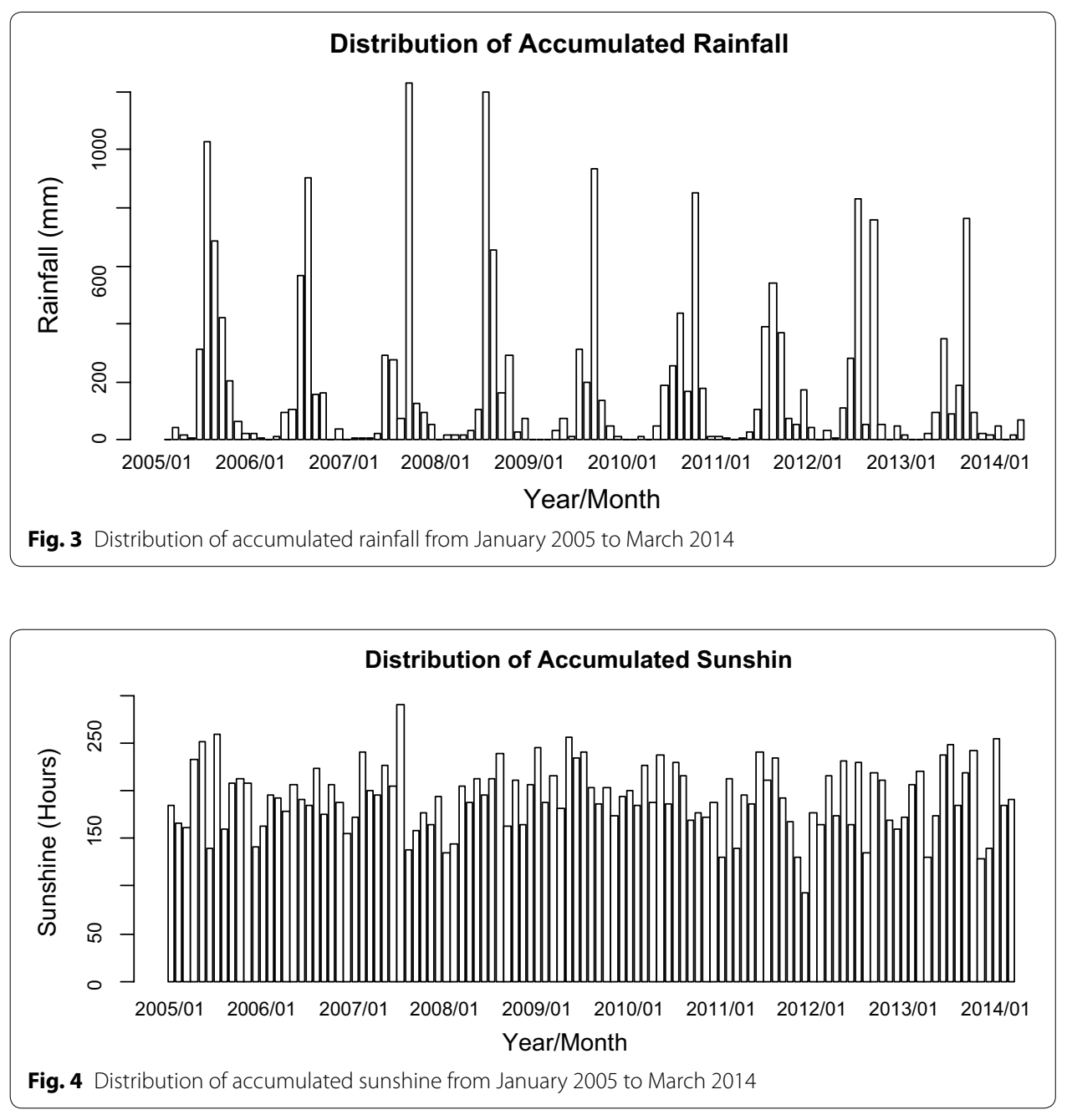

\begin{tabular}{lcccc}
$\begin{array}{l}\text { Table } 3 \text { Regression } \\
\text { in southern Taiwan }\end{array}$ & analysis of climatic & factor & affecting & dengue \\
& Estimate & S.E. & t-value & incidence \\
\hline Intercept & 3.118 & 66.797 & 0.047 & p-value \\
Temperature & 6.289 & 2.756 & 2.282 & 0.963 \\
Rainfall & -0.144 & 0.072 & -2.002 & 0.024 \\
Sunshine & -1.025 & 0.368 & -2.790 & 0.047 \\
\hline
\end{tabular}

The predictive model equation plots dengue fever incidence (cases) versus temperature $\left({ }^{\circ} \mathrm{C}\right)$, accumulated rainfall $(\mathrm{mm})$, and accumulated sunshine (hours) is as follows:

$$
\begin{aligned}
\text { Dengue fever incidence }= & 3.118+6.289 \times \text { temperature } \\
& +(-0.144) \times \text { rainfall }+(-1.025) \times \text { sunshine }
\end{aligned}
$$

The results demonstrate that climatic factors are associated with dengue fever cases. Table 3 shows that, first, monthly temperature $(\mathrm{t}$-value $=2.282, p$ value $=0.024)$ is positively correlated with the dengue fever cases, and this result is in agreement with 


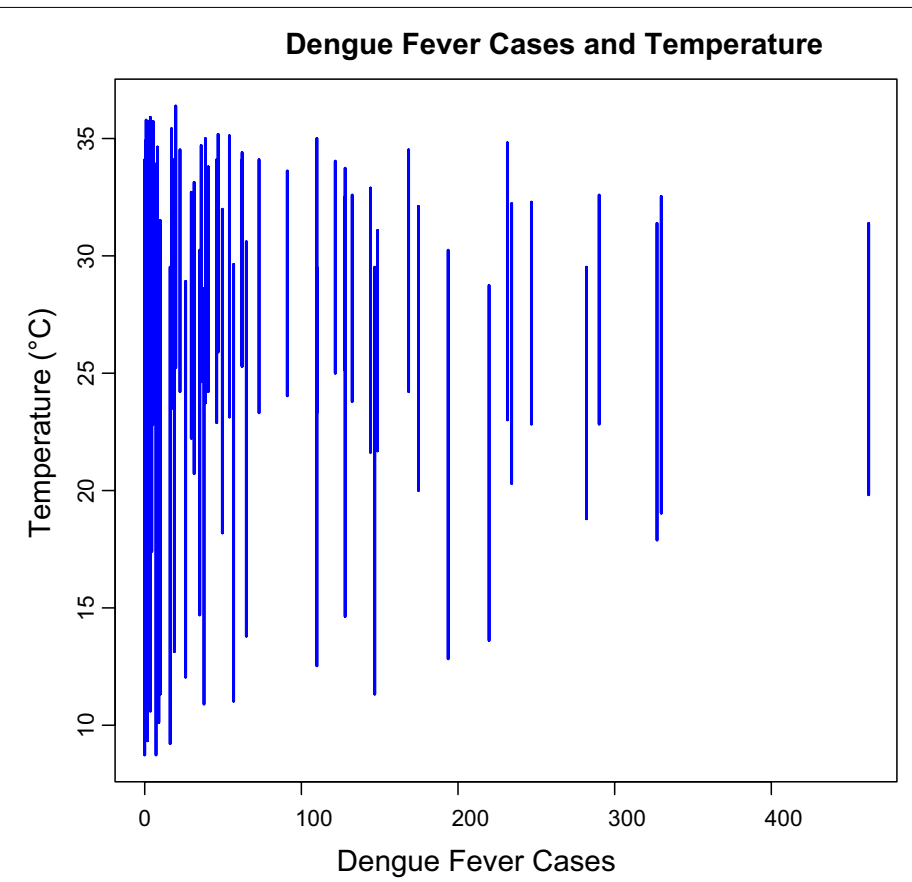

Fig. 5 The symbolic scatter plot of dengue fever cases with accumulated temperature

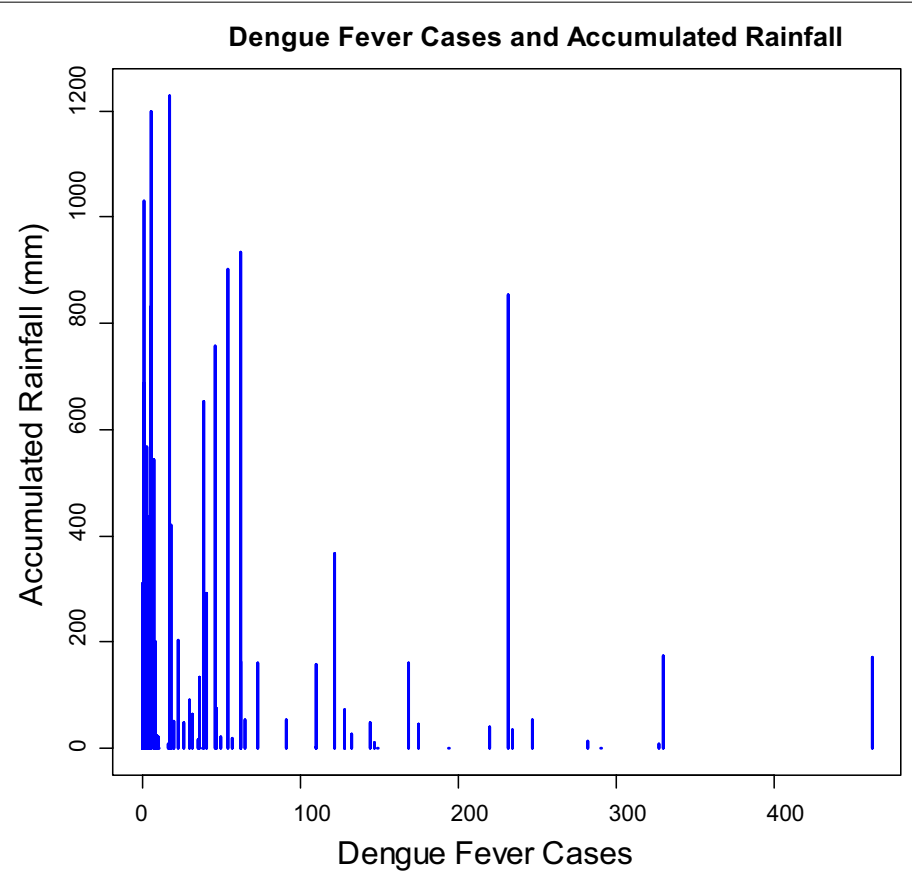

Fig. 6 The symbolic scatter plot of dengue fever cases with accumulated rainfall

previous studies [6-10, 14, 23]. Second, same with Wegbreit's study [26] and Alshehri's study [22], accumulated rainfall ( $\mathrm{t}$-value $=-2.002$, $\mathrm{p}$-value $=0.047$ ) is negatively correlated with the dengue fever cases. Third, accumulated sunshine ( $\mathrm{t}$-value $=-2.790$, 


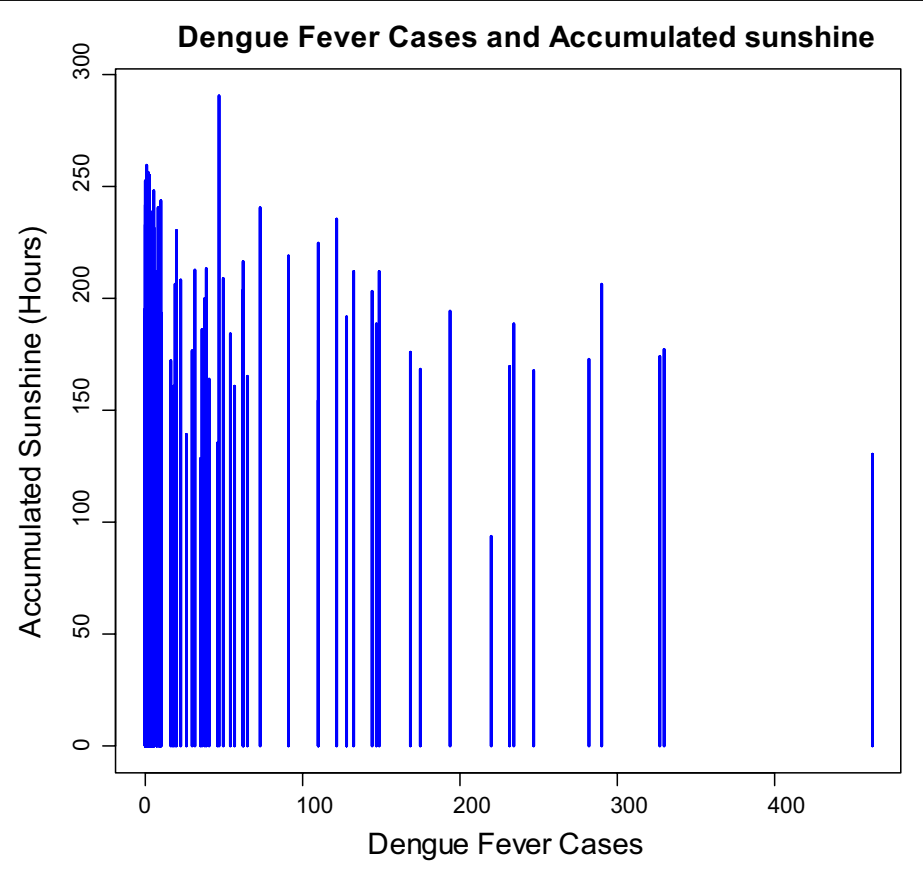

Fig. 7 The symbolic scatter plot of dengue fever cases with accumulated sunshine

$\mathrm{p}$-value $=0.007)$ is also negatively correlated with the dengue fever cases, and this result supports Vu, Okumura, Hashizume, Tran, and Yamamoto's research [15]. The symbolic scatter plot of dengue fever cases with temperature/accumulated rainfall/accumulated sunshine is presented in Figs. 5, 6, and 7. The r-squared value is .138, which indicates that $13.8 \%$ of the error is explained by the model.

\section{Discussion}

From the study that has been carried out, it is possible to conclude that the risk of dengue fever is positively associated with high temperature, but inversely associated with duration of rainfall and sunshine. This result is consistent with findings of most of the previous studies.

This study shows that temperature is significantly associated with dengue fever incidence. As the temperature increases, the transmission rate of dengue fever also increases. The weight of temperature is larger than others in the predictive model, and it is possible that temperature plays an important role in most of the physiological functions of vectors in southern Taiwan. Temperature is an important climatic factor affecting biological processes of mosquitoes, including their interactions with viruses. Temperature is also positively associated with pre-adult mosquito maturation, oviposition rate, and virus incubation rate in mosquitos [11].

It is found in this study that rainfall and sunshine are both negatively associated with the transmission of dengue fever in southern Taiwan. Figure 2 shows that heavy rainfalls are frequent in southern Taiwan. According to previous studies [16, 22, 26], heavy rainfalls may not favor mosquito density as most of the mosquito eggs and larvae would be washed away from breeding sites [26]. This argument may explain why dengue fever decreases as rainfall increases in southern Taiwan. 
Sunshine is also closely linked to other ecological factors such as temperature and thereby might affect the dengue fever incidence. The longer the hours of sunshine, the higher of the temperature is. Although warmer temperatures can increase the transmission rates of dengue fever in various ways, many studies have concluded that high temperature may not favor mosquito density as most of the mosquito larvae would die in heat [19]. This may be the reason why previous studies $[10,19,20]$ indicated that maximum temperature and sunshine are negatively correlated with dengue fever incidence.

\section{Conclusions}

Dengue fever is ubiquitous throughout the tropics. With spatial variation in different regions, the effects of climate on dengue fever are also different. Dengue viruses and their mosquito vectors are sensitive to their environment. Temperature, rainfall and sunshine have well-defined roles in the transmission cycle. Findings of this paper suggest that control of mosquito by climatic factor during high temperature seasons may be an important strategy for containing the burden of dengue fever.

This study only concentrated on climatic factors. However, some studies [29] showed a clear relationship between sociological factors (e.g., population, urbanization public health policy, and health education) and dengue fever. Further research can continue to test and verify those. In addition, this study focused on Taiwan. Taiwan is a region that is influenced deeply by Chinese culture, so this study can be seen as an example of how climatic factors affect dengue fever in Chinese lifestyle. Future research can further explore how lifestyles in different cultures can influence the occurrence of dengue fever.

Declarations

Author's contributions The author of this manuscript is YHL. The author has made substantial contributions to the conception and design, acquisition, analysis and interpretation of data, and he was involved in drafting the manuscript. The author read and approved the final manuscript.

Acknowledgements

This study is based in part on data from Taiwan National Infectious Disease Statistics System provided by Taiwan's Centers for Disease Control Taiwan. The interpretation and conclusions contained herein do not represent those of Taiwan National Infectious Disease Statistics System or Taiwan's Centers for Disease Control.

Competing interests

The author declare that he has no competing interests.

Availability of data and materials

All data analyzed during this study are included in this published article.

Consent for publication

Not applicable.

Ethics approval and consent to participate

Not applicable.

Funding

Not applicable. This study is not funded by any organization.

About this supplement

This article has been published as part of BioMedical Engineering OnLine Volume 17 Supplement 2, 2018: Proceedings of the International Conference on Biomedical Engineering Innovation (ICBEI) 2016. The full contents of the supplement are available online at https://biomedical-engineering-online.biomedcentral.com/articles/supplements/volume-17-suppl ement-2. 


\section{Publisher's Note}

Springer Nature remains neutral with regard to jurisdictional claims in published maps and institutional affiliations.

Published: 6 November 2018

\section{References}

1. World Health Organization (WHO), Epidemiology. Dengue Control. 2016. http://www.who.int/denguecontrol/en/. Accessed 30 Sept 2017.

2. Hales S, Weinstein P, Souares $Y$, Woodward A. El Niño and the dynamics of vectorborne disease transmission. Environ Health Perspect. 1999;107(2):99-102.

3. Hales S, de Wet N, Maindonaid J, Woodward A. Potential effect of population and climatic changes on global distribution of dengue fever: an empirical model. Lancet. 2002;360(9336):830-4.

4. Yu HL, Angulo JM, Cheng MH, Wu J, Christakos G. An online spatiotemporal prediction model for dengue fever epidemic in Kaohsiung (Taiwan). Biometrical J. 2014;56(3):428-40.

5. Centers for Disease Control (Taiwan), Denque Fever. Communicable Diseases \& Prevention. 2015. http://www.cdc gov.tw/english/info.aspx?treeid=e79c7a9e1e9b1cdf\&nowtreeid=e02c24f0dacdd729\&tid=D76AD76D26365478. Accessed 30 Sept 2017.

6. Tseng YT, Chang FS, Chao DY, Lian IB. Re-model the relation of vector indices, meteorological factors and dengue fever. J Trop Dis. 2016. https://doi.org/10.4172/2329-891X.1000200.

7. Nakhapakorn K, Tripathi NK. An information value based analysis of physical and climatic factors affecting dengue fever and dengue haemorrhagic fever incidence. Int J Health Geogr. 2005; 4(13). http://ij-healthgeographics.biome dcentral.com/articles/10.1186/1476-072X-4-13. Accessed 30 June 2016

8. Hau VP, Huong TMD, Thao TTP, Nguyen NTM. Ecological factors associated with dengue fever in a central highlands Province, Vietnam. BMC Infect Dis. 2011; 11(172). https://bmcinfectdis.biomedcentral.com/articles/10.1186/14712334-11-172. Accessed 30 June 2016.

9. Tong MX, Hansen A, Hanson-Easey S, Xiang J, Cameron S, Liu Q, Liu X, Sun Y, Weinstein P, Han GS, Williams C, Bi P. Perceptions of capacity for infectious disease control and prevention to meet the challenges of dengue fever in the face of climate change: a survey among CDC staff in Guangdong Province, China. Environ Res. 2016;148:295-302.

10. Choi Y, Tang CS, Mclver L, Hashizume M, Chan V, Abeyasinghe RR, Iddings S, Huy R. Effects of weather factors on dengue fever incidence and implications for interventions in Cambodia. BMC Public Health. 2016; 16(241). https:// bmcpublichealth.biomedcentral.com/articles/10.1186/s12889-016-2923-2. Accessed 30 June 2016.

11. Chen SC, Hsieh MH. Modeling the transmission dynamics of dengue fever: implications of temperature effects. Sci Total Environ. 2012:431:385-91.

12. Wu PC, Guo HR, Lung SC, Lin CY, Su HJ. Weather as an effective predictor for occurrence of dengue fever in Taiwan. Acta Trop. 2007;103(1):50-7.

13. Chang K, Lee NY, Ko WC, Tsai JJ, Lin WR, Chen TC, Lu PL, Chen YH. Identification of factors for physicians to facilitate early differential diagnosis of scrub typhus, murine typhus, and Q fever from dengue fever in Taiwan. J Microbio Immunol Infect. 2015. https://doi.org/10.1016/j.jmii.2014.12.001.

14. Hii YL, Zhu H, Ng N, Ng LC, Rocklöv J. Forecast of dengue incidence using temperature and rainfall. PLOS Negl Trop Dis. 2012. https://doi.org/10.1371/journal.pntd.0001908.

15. Vu HH, Okumura J, Hashizume M, Tran M, Yamamoto T. Regional differences in the growing incidence of dengue fever in Vietnam explained by weather variability. Trop Med Health. 2014;42(1):25-33.

16. Thammapalo S, Chongsuwiwatwong V, McNeil D, Geater A. The climatic factors influencing the occurrence of dengue hemorrhagic fever in Thailand. Southeast Asian J Trop Med Public Health. 2005;36(1):191-6.

17. Jin X, Lee M, Shu J. Dengue fever in China: an emerging problem demands attention. Emerg Microb Infect. 2015; 4(e3). http://www.nature.com/emi/journal/v4/n1/full/emi20153a.html. Accessed 30 June 2016.

18. Chadee DD, Shivnauth B, Rawlins SC, Chen AA. Climate, mosquito indices and the epidemiology of dengue fever in Trinidad (2002-2004). Ann Trop Med Parasitol. 2007;101(1):69-77.

19. Wongkoon S, Jaroensutasinee $M$, Jaroensutasinee K. Distribution, seasonal variation and dengue transmission prediction in Sisaket, Thailand. Indian J Med Res. 2013;138(3):347-53.

20. Cheong YL, Burkart K, Leitão PJ, Lakes T. Assessing weather effects on dengue disease in Malaysia. Int J Environ Res Public Health. 2013;10(12):6319-34.

21. Méndez-Lázaro P, Muller-Karger FE, Otis D, McCarthy MJ, Peña-Orellana M. Assessing climate variability effects on dengue incidence in San Juan, Puerto Rico. Int J Environ Res Public Health. 2014;11(9):9409-28.

22. Alshehri MSA. Dengue fever outburst and its relationship with climatic factors. World Appl Sci J. 2013;22(4):506-15.

23. Bhatt S, Gething PW, Brady OJ, Messina JP, Farlow AW, Moyes CL, Drake JM, Brownstein JS, Hoen AG, Sankoh O, Myers MF, George DB, Jaenisch T, Wint GRW, Simmons GP, Scott TW, Farrar JJ, Hay SI. The global distribution and burden of dengue. Nature. 2013;496(7446):504-7.

24. Teurlai M, Menkès CE, Cavarero V, Degallier N, Descloux E, Grangeon JP, Guillaumot L, Libourel T, Lucio PS, MathieuDaudé F, Mangeas M. Socio-economic and climate factors associated with dengue fever spatial heterogeneity: a worked example in New Caledonia. PLOS Negl Trop Dis. 2015. https://doi.org/10.1371/journal.pntd.0004211.

25. Promprou S, Jaroensutasinee M, Jaroensutasinee K. Climatic factors affecting dengue haemorrhagic fever incidence in southern Thailand. Dengue Bull. 2005;29:41-8.

26. Wegbreit J. The possible effects of temperature and precipitation on dengue morbidity in Trinidad and Tobago: a retrospective longitudinal study. Population-Environment Dynamics: Issues and Policy (University of Michigan, School of Natural Resources and Environment). 1997. http://www.umich.edu/ csfound/545/1997/weg/. Accessed 30 June 2016 
27. Goto K, Kumarendran B, Mettananda S, Gunasekara D, Fujii Y, Kaneko S. Analysis of effects of meteorological factors on dengue incidence in Sri Lanka using time series data. PLoS ONE. 2013; 8(5). http://journals.plos.org/plosone/artic le/asset?id=10.1371\%2Fjournal.pone.0063717.PDF. Accessed 30 June 2016.

28. Pandey N, Nagar R, Gupta S, Khan OD, Singh DD, Mishra G, Prakash S, Singh KP, Singh M, Jain A. Trend of dengue virus infection at Lucknow, north India (2008-2010): a hospital based study. Indian J Med Res. 2012;136(5):862-7.

29. Yang T, Lu L, Fu G, Zhong S, Ding G, Xu R, Zhu G, Shi N, Fan F, Liu Q. Epidemiology and vector efficiency during a dengue fever outbreak in Cixi, Zhejiang Province, China. J Vector Ecol. 2009;34(1):148-54.

30. Billard L, Diday E. Symbolic data analysis: conceptual statistics and data mining. New York: Wiley-Interscience; 2007.

31. Diday E, Monique NF. Symbolic data analysis and the SODAS software. New York: Wiley-Interscience; 2008.

32. Patz JA, Epstein PR, Burke TA, Balbus JM. Global climate change and emerging infectious diseases. JAMA. 1996;275(3):217-23.

33. Lai YH. Temperature factor affecting dengue fever incidence in southern Taiwan. Asian J Human Soc Stud. 2014;2(5):661-5.

34. The Ministry of Health and Welfare. Confirmed Cases of Dengue Fever, Taiwan National Infectious Disease Statistics System. http://nidss.cdc.gov.tw. Accessed 30 June 2016.

35. Central Weather Bureau. Daily Precipitation, Climate Statistics. http://www.cwb.gov.tw/V7/climate/monthlyData/ mD.htm. Accessed 30 June 2016.

36. Lima-Neto EA, de Carvalho FAT. Centre and range method to fitting a linear regression model on symbolic interval data. Comput Stat Data Anal. 2008;52:1500-15.

37. Lima-Neto EA, de Carvalho FAT. Constrained linear regression models for symbolic interval-valued variables. Comput Stat Data Anal. 2010;54:333-47.

- fast, convenient online submission

- thorough peer review by experienced researchers in your field

- rapid publication on acceptance

- support for research data, including large and complex data types

- gold Open Access which fosters wider collaboration and increased citations

- maximum visibility for your research: over 100M website views per year

At BMC, research is always in progress.

Learn more biomedcentral.com/submissions 